\title{
Research on Evaluating Algorithms for the Service Quality of Wireless Sensor Networks Based on Interval-Valued Intuitionistic Fuzzy EDAS and CRITIC Methods
}

\author{
Shihui Li (iD) and Bo Wang \\ School of Electro-Mechanical and Informaiton, Yiwu Industrial \& Commercial College, Yiwu 322000, China \\ Correspondence should be addressed to Shihui Li; 2003010164@ywicc.edu.cn
}

Received 28 March 2020; Revised 17 June 2020; Accepted 30 June 2020; Published 22 July 2020

Academic Editor: Harish Garg

Copyright (c) 2020 Shihui Li and Bo Wang. This is an open access article distributed under the Creative Commons Attribution License, which permits unrestricted use, distribution, and reproduction in any medium, provided the original work is properly cited.

\begin{abstract}
Wireless sensor networks play an important role in economic production and social life. However, in recent years, the number of wireless sensor network vulnerabilities has been increasing rapidly, which makes wireless sensor networks face more and more severe challenges. It is of great significance to realize the quantitative evaluation of wireless sensor networks in order to maintain the service quality of wireless sensor networks more effectively. The evaluating problem of the service quality of wireless sensor networks is a kind of multiple attribute group decision-making (MAGDM) problem. In this paper, depending on the classical EDAS method, the EDAS method will be extended to interval-valued intuitionistic fuzzy sets (IVIFSs) to address some MAGDM issues. At first, some essential concepts of IVIFSs are briefly reviewed. Subsequently, relying on the CRITIC method, the attributes' weights are decided. Furthermore, integrating the EDAS method with IVIFSs, IVIF-EDAS method is established, and all calculating procedures are depicted. Finally, an empirical application for evaluating the service quality of wireless sensor networks is given to demonstrate this novel algorithm, and some comparative analyses are made to confirm the merits of the designed method.
\end{abstract}

\section{Introduction}

In order to improve the accuracy of real-life decisionmaking, Zadeh [1] initially designed the fuzzy sets (FSs). Atanassov [2] designed the intuitionistic fuzzy sets (IFSs), which could be a generalization of FSs. In IFSs, there are three mathematical functions expressing the degrees of membership, nonmembership, and hesitancy. And they must satisfy the only condition that their sum of three degrees cannot exceed one. Gou et al. [3] pointed out a novel exponential operational law about IFNs and offered a method which was utilized to aggregate intuitionistic fuzzy information. He et al. [4] integrated the power averaging operators with IFSs and defined several intuitionistic fuzzy power interaction aggregation operators. Zhang and $\mathrm{He}$ [5] defined the extensions of intuitionistic fuzzy geometric interaction operators by using the $t$-norm and the corresponding $t$-conorm means. $\mathrm{Li}$ and $\mathrm{Wu}[6]$ presented the intuitionistic fuzzy cross-entropy distance and the GRA. Liang et al. [7] extended the MABAC method to IFSs by utilizing the novel distance measures. Khan and Lohani [8] put forward a novel similarity measure about IFNs depending on the distance measure of the double sequence of bounded variation. Chen et al. [9] developed the novel MCDM method based on the TOPSIS method and similarity measures in the context of IFSs. Li et al. [10] developed a grey target decision-making method in the form of IFNs on the basis of grey relational analysis [11]. Garg [12] developed some intuitionistic fuzzy averaging operators by taking the degrees of hesitation between the membership mathematical functions into consideration. Gupta et al. [13] extended the fuzzy entropy [14] to IFSs with axiomatic justification and proposed the importance of parameter alpha. Bao et al. [15] put forward the prospect theory and the evidential reasoning method under IFSs. Gan and Luo [16] employed a hybrid method on the basis of DEMATEL and IFSs. Gupta et al. [17] 
modified the superiority and inferiority ranking (SIR) method and combined it under IFSs. Krishankumar et al. [18] developed IFSP (intuitionistic fuzzy set-based PROMETHEE) which was a novel ranking method. Luo and Wang [19] combined IFSs with the VIKOR method relying on a novel distance measure by taking the IFSs into consideration. Hao et al. [20] presented the novel intuitionistic fuzzy MADM method depending on the decision theory. Zhang et al. [21] defined the intuitionistic fuzzy TOPSIS method based on CVPIFRS models with an application to biomedical problems. Garg [22] developed the generalized intuitionistic fuzzy entropy-based approach for solving multiattribute decision-making problems with unknown attribute weights. Liu et al. [23] presented some novel intuitionistic fuzzy operators by extending the BM operator on the basis of the Dombi operations [24] and designed some MAGDM methods. Jin et al. [25] developed two group decision-making (GDM) methods which could obtain the normalized intuitionistic fuzzy priority weights from the designed IFPRs on the basis of the order consistency and the multiplicative consistency. Wu et al. [26] gave VIKOR algorithms for assessing the financing risk about rural tourism projects under IVIFSs. Wu et al. [27] designed the algorithms for evaluating the competitiveness of tourist destination with some IVIF Hamy mean operators. Wu et al. [28] proposed some IVIF Dombi Heronian mean operators for evaluating the ecological tourism value. Chen and Kuo [29] presented the novel MADM method using the nonlinear programming (NLP) model with hyperbolic tangent function and IVIFSs. Lu and Wei [30] proposed the TODIM method for social-integrationbased rural performance appraisal under IVIFSs and integrated the ELECTRE method with IFSs to tackle some MCDM issues. Garg and Kumar [31] defined the group decision-making approach based on possibility degree measures and the linguistic intuitionistic fuzzy aggregation operators using Einstein norm operations. Garg and Arora [32] proposed the generalized intuitionistic fuzzy soft power aggregation operator based on the $t$-norm and its application in multicriteria decision-making.

Keshavarz Ghorabaee et al. [33] designed the evaluation based on distance from average solution (EDAS) to solve multicriteria inventory classification (MCIC) issues. In recent years, this method was enriched by the related extensions. For example, Ghorabaee et al. [34] modified such an EDAS method to tackle supplier selection issues. Keshavarz Ghorabaee et al. [35] presented the EDAS method with normal distribution to tackle stochastic issues. Peng and Liu [36] designed the neutrosophic soft MADM algorithms on the basis of EDAS and defined the similarity measure. Kahraman et al. [37] integrated the EDAS method with IFSs to select the solid waste disposal site. He et al. [38] designed the EDAS model for MAGDM with PULTSs. Keshavarz Ghorabaee et al. [39] made some comparative analyses about the phenomenon of order reversal depending on EDAS and TOPSIS. Wang et al. [40] proposed the EDAS model for MAGDM under the 2tuple linguistic neutrosophic environment. Li et al. [41] defined the EDAS for MAGDM issues under the q-rung orthopair fuzzy environment. Feng et al. [42] integrated the EDAS with the extended hesitant fuzzy linguistic environment. Karasan and Kahraman [43] designed the interval-valued neutrosophic EDAS to decision-making issues.

Unfortunately, we failed to find the work of the EDAS method based on the CRITIC method with IVIFSs in the existing literature. So, investigating the EDAS method with IVIFSs is essential. The fundamental objective of our research is to develop an original method which can be more effectively to address some MAGDM issues in the context of the EDAS method and IVIFSs. Hence, the highlights of this work are illustrated subsequently. Above all, the EDAS method is extended to the IVIFSs. In addition, because the DMs are restrained by their knowledge, it is tricky to assign the criteria weights directly. Hence, the CRITIC method is utilized to decide each attribute's weight. Last but not the least, an empirical application is offered to demonstrate this novel approach, and several comparative analyses are offered to demonstrate some merits of the novel approach.

However, there are no studies on the EDAS method for MAGDM under IVIFSs in the existing literature. Therefore, it is necessary to pay attention to this issue. The innovativeness of the paper can be summarized as follows: (1) the EDAS method is modified by IVIFSs; (2) the interval-valued intuitionistic fuzzy EDAS (IVIF-EDAS) method is designed to solve the MAGDM issues with IVIFSs; (3) a case study for evaluating the service quality of wireless sensor networks is designed to prove the developed method; and (4) some comparative studies are given to verify the rationality of the IVIF-EDAS method.

The reminder of our essay proceeds as follows. Some fundamental knowledge of IVIFSs is concisely reviewed in Section 2. The extended EDAS method is integrated with IVIFSs, and the calculating procedures are simply depicted in Section 3. An empirical application for assessing the service quality of wireless sensor networks is given to show the superiority of this approach, and some comparative analyses are offered to prove some merits of such a method in Section 4. At last, we make an overall conclusion of such a work in Section 5.

\section{Preliminaries}

Definition 1 (see [2]). The interval-valued IFSs (IVIFSs) on $X$ are the object of the form

$$
I=\left\{\left\langle x, \tilde{\mu}_{I}(x), \widetilde{v}_{I}(x)\right\rangle \mid x \in X\right\},
$$

where $\tilde{\mu}_{I}(x) \subset[0,1]$ is the "membership degree of $I$ " and $\widetilde{\nu}_{I}(x) \subset[0,1]$ is named the "nonmembership degree of $I$," and $\widetilde{\mu}_{I}(x)$ and $\widetilde{v}_{I}(x)$ meet the mathematical condition: $0 \leq \sup \tilde{\mu}_{I}(x)+\sup \widetilde{v}_{I}(x) \leq 1, \forall x \in X$. For convenience, we call $I=\left(\left[\mu^{L}, \mu^{R}\right],\left[v^{L}, v^{R}\right]\right)$ as an IVIFN.

Definition 2 (see [44]). Let $I_{1}=\left(\left[\mu_{1}^{L}, \mu_{1}^{R}\right],\left[\nu_{1}^{L}, v_{1}^{R}\right]\right)$ and $I_{2}=$ $\left(\left[\mu_{2}^{L}, \mu_{2}^{R}\right],\left[v_{2}^{L}, v_{2}^{R}\right]\right)$ be two IVIFNs; the operation formula of them can be defined as follows: 


$$
I_{1} \oplus I_{2}=\left(\left[\mu_{1}^{L}+\mu_{2}^{L}-\mu_{1}^{L} \mu_{2}^{L}, \mu_{1}^{R}+\mu_{2}^{R}-\mu_{1}^{R} \mu_{2}^{R}\right],\left[v_{1}^{L} v_{2}^{L}, v_{1}^{R} v_{2}^{R}\right]\right)
$$

$$
I_{1} \otimes I_{2}=\left(\left[\mu_{1}^{L} \mu_{2}^{L}, \mu_{1}^{R} \mu_{2}^{R}\right],\left[v_{1}^{L}+v_{2}^{L}-v_{1}^{L} v_{2}^{L}, v_{1}^{R}+v_{2}^{R}-v_{1}^{R} v_{2}^{R}\right]\right),
$$

$\lambda I_{1}=\left(\left[1-\left(1-\mu_{1}^{L}\right)^{\lambda}, 1-\left(1-\mu_{1}^{R}\right)^{\lambda}\right],\left[\left(v_{1}^{L}\right)^{\lambda},\left(v_{1}^{R}\right)^{\lambda}\right]\right), \quad \lambda>0$,

$I_{1}^{\lambda}=\left(\left[\left(\mu_{1}^{L}\right)^{\lambda},\left(\mu_{1}^{R}\right)^{\lambda}\right],\left[1-\left(1-\lambda_{1}^{L}\right)^{\lambda}, 1-\left(1-\lambda_{1}^{R}\right)^{\lambda}\right]\right), \quad \lambda>0$.

Derived from Definition 2, the following properties of the operation laws can be obtained:

(1) $I_{1} \oplus I_{2}=I_{2} \oplus I_{1}, I_{1} \otimes I_{2}=I_{2} \otimes I_{1},\left(\left(I_{1}\right)^{\lambda_{1}}\right)^{\lambda_{2}}=\left(I_{1}\right)^{\lambda_{1} \lambda_{2}}$

(2) $\lambda\left(I_{1} \oplus I_{2}\right)=\lambda I_{1} \oplus \lambda I_{2},\left(I_{1} \otimes I_{2}\right)^{\lambda}=\left(I_{1}\right)^{\lambda} \otimes\left(I_{2}\right)^{\lambda}$

(3) $\lambda_{1} I_{1} \oplus \lambda_{2} I_{1}=\left(\lambda_{1}+\lambda_{2}\right) I_{1},\left(I_{1}\right)^{\lambda_{1}} \otimes\left(I_{1}\right)^{\lambda_{2}}=\left(I_{1}\right)^{\left(\lambda_{1}+\lambda_{2}\right)}$

Definition 3 (see [45]). Let $I_{1}=\left(\left[\mu_{1}^{L}, \mu_{1}^{R}\right],\left[\nu_{1}^{L}, v_{1}^{R}\right]\right)$ and $I_{2}=$ $\left(\left[\mu_{2}^{L}, \mu_{2}^{R}\right],\left[\nu_{2}^{L}, \nu_{2}^{R}\right]\right)$ be IVIFNs; the score and accuracy values of $I_{1}$ and $I_{2}$ can be defined as follows:

$$
\begin{aligned}
& S\left(I_{1}\right)=\frac{\mu_{1}^{L}+\mu_{1}^{L}\left(1-\mu_{1}^{L}-v_{1}^{L}\right)+\mu_{1}^{R}+\mu_{1}^{R}\left(1-\mu_{1}^{R}-v_{1}^{R}\right)}{2}, \\
& S\left(I_{2}\right)=\frac{\mu_{2}^{L}+\mu_{2}^{L}\left(1-\mu_{2}^{L}-v_{2}^{L}\right)+\mu_{2}^{R}+\mu_{2}^{R}\left(1-\mu_{2}^{R}-v_{2}^{R}\right)}{2}, \\
& H\left(I_{1}\right)=\frac{\mu_{1}^{L}+v_{1}^{L}+\mu_{1}^{R}+v_{1}^{R}}{2}, \\
& H\left(I_{2}\right)=\frac{\mu_{2}^{L}+v_{2}^{L}+\mu_{2}^{R}+v_{2}^{R}}{2} .
\end{aligned}
$$

For two IFNs $I_{1}$ and $I_{2}$, regarding Definition 3,

(1) If $s\left(I_{1}\right)<s\left(I_{2}\right)$, then $I_{1}<I_{2}$

(2) If $s\left(I_{1}\right)>s\left(I_{2}\right)$, then $I_{1}>I_{2}$

(3) If $s\left(I_{1}\right)=s\left(I_{2}\right)$ and $h\left(I_{1}\right)<h\left(I_{2}\right)$, then $I_{1}<I_{2}$

(4) If $s\left(I_{1}\right)=s\left(I_{2}\right)$ and $h\left(I_{1}\right)>h\left(I_{2}\right)$, then $I_{1}>I_{2}$

(5) If $s\left(I_{1}\right)=s\left(I_{2}\right)$ and $h\left(I_{1}\right)=h\left(I_{2}\right)$, then $I_{1}=I_{2}$

Under the context of the IVIFNs, some aggregation operators will be introduced in this chapter, including the interval-valued intuitionistic fuzzy WA (IVIFWA) operator and the interval-valued intuitionistic fuzzy WG (IVIFWG) operator.

Definition 4 (see [44]). Let $I_{j}=\left(\mu_{I_{j}}, \nu_{I_{j}}\right)(j=1,2, \ldots, n)$ be a set of IVIFNs; the IVIFWA operator is defined as

$$
\operatorname{IVIFWA}_{\omega}\left(I_{1}, I_{2}, \ldots, I_{n}\right)=\oplus_{j=1}^{n}\left(\omega_{j} I_{j}\right) \text {, }
$$

where $\omega=\left(\omega_{1}, \omega_{2}, \ldots, \omega_{n}\right)^{T}$ is the weight vector of $I_{j}(j=$ $1,2, \ldots, n)$ and $\omega_{j}>0, \sum_{j=1}^{n} \omega_{j}=1$.

Derived from Definition 4 , the subsequent result can be obtained:

Theorem 1. The fused value by the IVIFWA operator could also be an IVIFN, where

$$
\begin{aligned}
& \operatorname{IVIFWA}_{\omega}\left(I_{1}, I_{2}, \ldots, I_{n}\right)=\oplus_{j=1}^{n}\left(\omega_{j} I_{j}\right) \\
& =\left(\left[1-\prod_{j=1}^{n}\left(1-\mu_{I_{j}}^{L}\right)^{\omega_{j}}, 1-\prod_{j=1}^{n}\left(1-\mu_{I_{j}}^{R}\right)^{\omega_{j}}\right],\left[\prod_{j=1}^{n}\left(v_{I_{j}}^{L}\right)^{\omega_{j}}, \prod_{j=1}^{n}\left(v_{I_{j}}^{R}\right)^{\omega_{j}}\right]\right),
\end{aligned}
$$

where $\omega=\left(\omega_{1}, \omega_{2}, \ldots, \omega_{n}\right)^{T}$ is the weight vector of $I_{j}(j=$ $1,2, \ldots, n)$ and $\omega_{j}>0, \sum_{j=1}^{n} \omega_{j}=1$.

Definition 5 (see [44]). Let $I_{j}(j=1,2, \ldots, n)$ be a set of IVIFNs; the IVIFWG operator can be given as

$$
\operatorname{IVIFWG}_{\omega}\left(I_{1}, I_{2}, \ldots, I_{n}\right)=\otimes_{j=1}^{n}\left(I_{j}\right)^{\omega_{j}},
$$

where $\omega=\left(\omega_{1}, \omega_{2}, \ldots, \omega_{n}\right)^{T}$ is the weight vector of $I_{j}(j=$ $1,2, \ldots, n)$ and $\omega_{j}>0, \sum_{j=1}^{n} \omega_{j}=1$.

Derived from Definition 5, the detailed result can be obtained.

Theorem 2. The fused value by using the IVIFWG operator could also be an IVIFN, where 


$$
\begin{aligned}
& \operatorname{IVIFWG}_{\omega}\left(I_{1}, I_{2}, \ldots, I_{n}\right)=\otimes_{j=1}^{n}\left(I_{j}\right)^{\omega_{j}} \\
& =\left(\left[\prod_{j=1}^{n}\left(\mu_{I_{j}}^{L}\right)^{\omega_{j}}, \prod_{j=1}^{n}\left(\mu_{I_{j}}^{R}\right)^{\omega_{j}}\right],\left[1-\prod_{j=1}^{n}\left(1-v_{I_{j}}^{L}\right)^{\omega_{j}}, 1-\prod_{j=1}^{n}\left(1-v_{I_{j}}^{R}\right)^{\omega_{j}}\right]\right),
\end{aligned}
$$

where $\omega=\left(\omega_{1}, \omega_{2}, \ldots, \omega_{n}\right)^{T}$ is the weight vector of $I_{j}(j=1,2, \ldots, n)$ and $\omega_{j}>0, \sum_{j=1}^{n} \omega_{j}=1$.

\section{The EDAS Method with IVIFNs}

Integrating the EDAS method with IVIFSs, we build the IVIF-EDAS method in which the assessment values are given by IVIFNs. The calculating procedures of the developed method can be described subsequently.

Let $Z=\left\{Z_{1}, Z_{2}, \ldots, Z_{n}\right\}$ be the attribute set and $z=\left\{z_{1}\right.$, $\left.z_{2}, \ldots, z_{n}\right\}$ be the attribute weight $Z_{j}$, where $z_{j} \in[0,1]$, $j=1,2, \ldots, n, \sum_{j=1}^{n} z_{j}=1$. Assume $D=\left\{D_{1}, D_{2}, \ldots, D_{l}\right\}$ is a set of decision makers that have a significant degree of $d=$ $\left\{d_{1}, d_{2}, \ldots, d_{l}\right\}$, where $d_{k} \in[0,1], k=1,2, \ldots, l ., \sum_{k=1}^{l} d_{k}=1$. Let $Y=\left\{Y_{1}, Y_{2}, \ldots, Y_{m}\right\}$ be a discrete collection of alternatives. And $Q=\left(q_{i j}\right)_{m \times n}$ is the overall IVIFN decision matrix; $q_{i j}$ means the value of alternative $Y_{i}$ regarding attribute $Z_{j}$. Subsequently, the specific calculating procedures will be depicted.

Step 1: set up each decision maker's IVIFN decision matrix $Q^{(k)}=\left(q_{i j}^{k}\right)_{m \times n}$, and calculate the overall IVIFN decision matrix $Q=\left(q_{i j}\right)_{m \times n}$ :

$$
\begin{aligned}
& Q^{(k)}=\left[q_{i j}^{k}\right]_{m \times n}=\left[\begin{array}{cccc}
q_{11}^{k} & q_{12}^{k} & \cdots & q_{1 n}^{k} \\
q_{21}^{k} & q_{22}^{k} & \cdots & q_{2 n}^{k} \\
\vdots & \vdots & \vdots & \vdots \\
q_{m 1}^{k} & q_{m 2}^{k} & \cdots & q_{m n}^{k}
\end{array}\right], \\
& Q=\left[q_{i j}\right]_{m \times n}=\left[\begin{array}{cccc}
q_{11} & q_{12} & \cdots & q_{1 n} \\
q_{21} & q_{22} & \cdots & q_{2 n} \\
\vdots & \vdots & \vdots & \vdots \\
q_{m 1} & q_{m 2} & \cdots & q_{m n}
\end{array}\right], \\
& q_{i j}=\left(\left[1-\prod_{k=1}^{l}\left(1-\mu_{q_{i j}^{k}}^{L}\right)^{d_{k}}, 1-\prod_{k=1}^{l}\left(1-\mu_{q_{i j}^{k}}^{R}\right)^{d_{k}}\right],\right. \\
&\left.\cdot\left[\prod_{k=1}^{l}\left(v_{q_{i j}^{k}}^{L}\right)^{d_{k}}, \prod_{k=1}^{l}\left(v_{q_{i j}^{k}}^{R}\right)^{d_{k}}\right]\right),
\end{aligned}
$$

where $q_{i j}^{k}$ is the assessment value of alternative $Y_{i}(i=$ $1,2, \ldots, m)$ on the basis of the attribute $Z_{j}(j=1,2$, $\ldots, n)$ and the decision maker $D_{k}(k=1,2, \ldots, l)$.

Step 2: normalize the overall IVIFN decision matrix $Q=\left(q_{i j}\right)_{m \times n}$ to $Q^{N}=\left[q_{i j}^{N}\right]_{m \times n}$ : $q_{i j}^{N}= \begin{cases}\left(\left[\mu_{i j}^{L}, \mu_{i j}^{R}\right],\left[v_{i j}^{L}, v_{i j}^{R}\right]\right), & Z_{j} \text { is a benefit criterion, } \\ \left(\left[v_{i j}^{L}, v_{i j}^{R}\right],\left[\mu_{i j}^{L}, \mu_{i j}^{R}\right]\right), & Z_{j} \text { is a cost criterion. }\end{cases}$

Step 3: utilize the CRITIC method to determine the weighting matrix of attributes.

CRiteria Importance through Intercriteria Correlation (CRITIC) method will be designed in this part which is utilized to decide attributes' weights. This method was initially put forward by Diakoulaki et al. [46] which took the correlations between attributes into consideration. Subsequently, the calculating procedures of this method will be presented:

(1) Depending on the normalized overall IVIFN decision matrix $Q^{N}=\left(q_{i j}^{N}\right)_{m \times n}$, the correlation coefficient between attributes can be calculated:

$$
\begin{aligned}
\mathrm{IC}_{j t}= & \frac{\sum_{i=1}^{m}\left(S\left(q_{i j}^{N}\right)-S\left(q_{j}^{N}\right)\right)\left(S\left(q_{i t}^{N}\right)-S\left(q_{t}^{N}\right)\right)}{\sqrt{\sum_{i=1}^{m}\left(S\left(q_{i j}^{N}\right)-S\left(q_{j}^{N}\right)\right)^{2}} \sqrt{\sum_{i=1}^{m}\left(S\left(q_{i t}^{N}\right)-S\left(q_{t}^{N}\right)\right)^{2}}}, \\
& j, t=1,2, \ldots, n,
\end{aligned}
$$

where $\quad q_{j}^{N}=1 / m \sum_{i=1}^{m} S\left(q_{i j}^{N}\right) \quad$ and $\quad q_{t}^{N}=1 / m$ $\sum_{i=1}^{m} S\left(q_{i t}^{N}\right)$.

(2) Calculate attributes' standard deviation:

$$
\mathrm{IS}_{j}=\sqrt{\frac{1}{m-1} \sum_{i=1}^{m}\left(S\left(q_{i j}^{N}\right)-S\left(q_{j}^{N}\right)\right)^{2}}, \quad j=1,2, \ldots, n,
$$

where $q_{j}^{N}=1 / m \sum_{i=1}^{m} S\left(q_{i j}^{N}\right)$.

(3) Calculate the attributes' weights:

$$
z_{j}=\frac{\mathrm{IS}_{j} \sum_{t=1}^{n}\left(1-\mathrm{IC}_{j t}\right)}{\sum_{j=1}^{n}\left(\mathrm{IS}_{j} \sum_{t=1}^{n}\left(1-\mathrm{IC}_{j t}\right)\right)}, \quad j=1,2, \ldots, n,
$$

where $z_{j} \in[0,1]$ and $\sum_{j=1}^{n} z_{j}=1$.

Step 4: calculate the average solution (AV) regarding all designed attributes:

$$
\mathrm{AV}=\left[\mathrm{AV}_{j}\right]_{1 \times n}=\left[\frac{\sum_{i=1}^{m} \widehat{q}_{i j}^{N}}{m}\right]_{1 \times n},
$$




$$
\begin{aligned}
& {\left[\mathrm{AV}_{j}\right]_{1 \times n}=\left[\frac{\sum_{i=1}^{m} \hat{q}_{i j}^{N}}{m}\right]_{1 \times n} } \\
= & \left(\begin{array}{c}
{\left[1-\prod_{i=1}^{m}\left(1-\left(\mu_{i j}^{N}\right)^{L}\right)^{1 / m}, 1-\prod_{i=1}^{m}\left(1-\left(\mu_{i j}^{N}\right)^{R}\right)^{1 / m}\right]} \\
{\left[\prod_{i=1}^{m}\left(\left(v_{i j}^{N}\right)^{L}\right)^{1 / m}, \prod_{i=1}^{m}\left(\left(v_{i j}^{N}\right)^{R}\right)^{1 / m}\right]}
\end{array}\right)_{1 \times n} .
\end{aligned}
$$

Step 5: depending on the AV's results, the positive distance from average (PDA) and negative distance from average (NDA) can be defined:

$$
\begin{aligned}
& \mathrm{PDA}_{i j}=\left[\mathrm{PDA}_{i j}\right]_{m \times n}=\frac{\max \left(0,\left(s\left(q_{i j}^{N}\right)-s\left(\mathrm{AV}_{j}\right)\right)\right)}{s\left(\mathrm{AV}_{j}\right)}, \\
& \mathrm{NDA}_{i j}=\left[\mathrm{NDA}_{i j}\right]_{m \times n}=\frac{\max \left(0,\left(s\left(\mathrm{AV}_{j}\right)-s\left(q_{i j}^{N}\right)\right)\right)}{s\left(\mathrm{AV}_{j}\right)} .
\end{aligned}
$$

Step 6: calculate $\mathrm{SP}_{i}$ and $\mathrm{SN}_{i}$ which express the weighted sum of PDA and NDA:

$$
\mathrm{SP}_{i}=\sum_{j=1}^{n} z_{j} \cdot \mathrm{PDA}_{i j}, \mathrm{NP}_{i}=\sum_{j=1}^{n} z_{j} \cdot \mathrm{NDA}_{i j}
$$

Step 7: depending on the above calculated results, $\mathrm{SP}_{i}$ and $\mathrm{SN}_{i}$ can be normalized as

$$
\begin{aligned}
\mathrm{NSP}_{i} & =\frac{\mathrm{SP}_{i}}{\max _{i}\left(\mathrm{SP}_{i}\right)}, \\
\mathrm{NSN}_{i} & =1-\frac{\mathrm{SN}_{i}}{\max _{i}\left(\mathrm{SN}_{i}\right)} .
\end{aligned}
$$

Step 8: calculate the appraisal score $\mathrm{AS}_{i}$ regarding every alternative's $\mathrm{NSP}_{i}$ and $\mathrm{NSN}_{i}$ :

$$
\mathrm{AS}_{i}=\frac{1}{2}\left(\mathrm{NSP}_{i}+\mathrm{NSN}_{i}\right)
$$

Step 9: according to $\mathrm{AS}_{i}$, all the alternatives can be ranked. The higher the value of $\mathrm{AS}_{i}$ is, the optimal alternative will be selected.

\section{The Empirical Example and Comparative Analysis}

4.1. An Empirical Example. With the development of research on wireless technique and other related techniques, wireless sensor networks (WSNs) have been widely used in various applications which involve diverse working environments, monitoring objects, and data conditions. Different applications require different quality of service (QoS) for data collection and data transmission. Thus, it is essential to provide QoS guarantee mechanisms in WSNs to achieve good performance in various applications. Accordingly, it is of great significance to study the QoS guarantee mechanisms in WSNs. In general terms, the QoS of WSNs focuses on timeliness and reliability of data transmission, as well as coverage and connectivity of the network topology for data collection. The QoS guarantee implementation relies on different mechanisms in WSNs. Although many methods and techniques have been proposed in the existing literature, the QoS guarantee mechanism is still faced with the following challenges in complex applications: (1) there exist several types of data traffic which have different QoS requirements. Therefore, a multiple-level QoS guarantee mechanism is in great demand. (2) There could be multiple QoS requirements for one data traffic. Thus, it is necessary to provide multiple-QoS guarantee mechanisms for theses traffics. (3) Since the traffic distributes are nonuniform in space and time, a method for the efficient transmission in a dynamic traffic is required. (4) There exists nonuniform replacement of the nodes as well as dynamic and changeful topology in many applications of the WSN. It is necessary to provide an efficient deployment method to satisfy the requirement of effectively covering. In this chapter, an empirical example for evaluating the service quality of wireless sensor networks which considered the complex MAGDM issues [47-54] will be provided by making use of the IVIF-EDAS method. Thus, in such a section, we present a numerical example to assess computer network systems with IVIFNs in order to show the designed method. There are five wireless sensor networks $A_{i}(i=1,2,3,4,5)$ to select. The expert group selects four attributes to evaluate these five wireless sensor networks: (1) $G_{1}$ is the product quality factor; (2) $G_{2}$ is the technology factor; (3) $G_{3}$ is the delivery factor; and (4) $G_{4}$ is the price factor. Taking its own business development into consideration, a company wants to choose a wireless sensor network. There are five potential wireless sensor networks $Y_{i}(i=1,2,3,4,5)$. In order to select the optimal wireless sensor network, the expert group invites five experts $D=$ $\left\{D_{1}, D_{2}, D_{3}, D_{4}, D_{5}\right\} \quad$ (expert's weight $d=(1 / 5,1 / 5$, $1 / 5,1 / 5,1 / 5))$ to assess these wireless sensor networks. All experts give their assessment information depending on the four subsequently attributes: (1) $Z_{1}$ is the traffic convenience; (2) $Z_{2}$ is the product price; (3) $Z_{3}$ is the green environmental protection ability; and (4) $Z_{4}$ is the service quality. Evidently, $Z_{2}$ is the $g$ cost attribute, while $Z_{1}, Z_{3}$, and $Z_{4}$ are the benefit attributes. To obtain the optimal wireless sensor network, the calculating procedures are involved:

Step 1: set up each decision maker's IVIFN evaluation matrix $Q^{(k)}=\left(q_{i j}^{k}\right)_{m \times n}(i=1,2, \ldots, m, j=1,2, \ldots, n)$ as in Tables 1-5. Derived from these tables and equations (12)-(14), the overall IVIFN decision matrix could be calculated. The results are recorded in Table 6 .

Step 2: normalize the evaluation matrix $Q=\left[q_{i j}\right]_{m \times n}$ to $Q^{N}=\left[q_{i j}^{N}\right]_{m \times n}$ (see Table 7$)$. 
TABLE 1: IVIFN evaluation information by $D_{1}$.

\begin{tabular}{ccccc}
\hline & $Z_{1}$ & $Z_{2}$ & $Z_{3}$ & $Z_{4}$ \\
\hline$Y_{1}$ & $([0.35,0.38],[0.58,0.62])$ & $([0.21,0.31],[0.33,0.69])$ & $([0.24,0.33],[0.41,0.66])$ & $([0.32,0.43][0.45,0.57)$ \\
$Y_{2}$ & $([0.29,0.39][0.44,0.61])$ & $([0.28,0.34],[0.46,0.64])$ & $([0.11,0.25],[0.32,0.75])$ & $([0.39,0.44],[0.52,0.61])$ \\
$Y_{3}$ & $([0.40,0.49],[0.51,0.60])$ & $([0.33,0.51],[0.53,0.67])$ & $([0.44,0.50],[0.52,0.56])$ & $([0.28,0.39],[0.61,0.72])$ \\
$Y_{4}$ & $([0.33,0.48],[0.54,0.67])$ & $([0.42,0.49],[0.51,0.58])$ & $([0.41,0.44],[0.46,0.59])$ & $([0.41,0.46],[0.49,0.53])$ \\
$Y_{5}$ & $([0.26,0.48],[0.61,0.74])$ & $([0.42,0.47],[0.52,0.58])$ & $([0.41,0.48],[0.51,0.59])$ & $([0.38,0.53],[0.55,0.62])$ \\
\hline
\end{tabular}

TABLE 2: IVIFN evaluation information by $D_{2}$.

\begin{tabular}{ccccc}
\hline & $Z_{1}$ & $Z_{2}$ & $Z_{3}$ & $Z_{4}$ \\
\hline$Y_{1}$ & $([0.38,0.42],[0.55,0.62])$ & $([0.43,0.49],[0.51,0.57])$ & $([0.29,0.39],[0.59,0.71])$ & $([0.45,0.48],[0.50,0.55])$ \\
$Y_{2}$ & $([0.37,0.48],[0.56,0.63])$ & $([0.34,0.44],[0.51,0.66])$ & $([0.46,0.50],[0.52,0.54])$ & $([0.39,0.48],[0.50,0.61])$ \\
$Y_{3}$ & $([0.37,0.50],[0.54,0.63])$ & $([0.27,0.39],[0.67,0.73])$ & $([0.41,0.52],[0.54,0.59])$ & $([0.16,0.33],[0.72,0.84])$ \\
$Y_{4}$ & $([0.46,0.49],[0.52,0.54])$ & $([0.32,0.38],[0.56,0.68])$ & $([0.37,0.43],[0.47,0.63])$ & $([0.29,0.34],[0.68,0.71])$ \\
$Y_{5}$ & $([0.40,0.48],[0.52,0.60])$ & $([0.46,0.49],[0.51,0.54])$ & $([0.42,0.47],[0.55,0.58])$ & $([0.33,0.38],[0.62,0.67])$ \\
\hline
\end{tabular}

TABLE 3: IVIFN evaluation information by $D_{3}$.

\begin{tabular}{ccccc}
\hline & $Z_{1}$ & $Z_{2}$ & $Z_{3}$ & $Z_{4}$ \\
\hline$Y_{1}$ & $([0.44,0.48],[0.52,0.56])$ & $([0.38,0.42],[0.48,0.62])$ & $([0.31,0.42],[0.59,0.69])$ & $([0.40,0.49],[0.58,0.60])$ \\
$Y_{2}$ & $([0.38,0.42],[0.59,0.62])$ & $([0.35,0.43],[0.58,0.65])$ & $([0.42,0.48],[0.52,0.58])$ & $([0.26,0.33],[0.59,0.74)$ \\
$Y_{3}$ & $([0.35,0.42],[0.59,0.65])$ & $([0.48,0.50],[0.51,0.52])$ & $([0.18,0.36],[0.64,0.82])$ & $([0.38,0.43],[0.56,0.62])$ \\
$Y_{4}$ & $([0.27,0.34],[0.59,0.73])$ & $([0.26,0.43],[0.62,0.74])$ & $([0.38,0.46],[0.52,0.62])$ & $([0.31,0.45],[0.62,0.69])$ \\
$Y_{5}$ & $([0.46,0.51],[0.52,0.54])$ & $([0.44,0.51],[0.52,0.56])$ & $([0.34,0.45],[0.62,0.66])$ & $([0.35,0.45],[0.55,0.65])$ \\
\hline
\end{tabular}

TABLE 4: IVIFN evaluation information by $D_{4}$.

\begin{tabular}{ccccc}
\hline & $Z_{1}$ & $Z_{2}$ & $Z_{3}$ & $Z_{4}$ \\
\hline$Y_{1}$ & $([0.42,0.48],[0.51,0.58])$ & $([0.37,0.44],[0.59,0.63])$ & $([0.25,0.37],[0.68,0.75])$ & $([0.22,0.35],[0.67,0.78])$ \\
$Y_{2}$ & $([0.41,0.49],[0.52,0.59])$ & $([0.36,0.39],[0.49,0.64])$ & $([0.27,0.43],[0.65,0.73])$ & $([0.42,0.45],[0.52,0.58])$ \\
$Y_{3}$ & $([0.43,0.48],[0.52,0.57])$ & $([0.42,0.48],[0.52,0.58])$ & $([0.41,0.48],[0.54,0.59])$ & $([0.34,0.49],[0.58,0.66])$ \\
$Y_{4}$ & $([0.32,0.43],[0.64,0.67])$ & $([0.32,0.43],[0.59,0.68])$ & $([0.36,0.39],[0.58,0.64])$ & $([0.15,0.39],[0.64,0.85])$ \\
$Y_{5}$ & $([0.37,0.45],[0.56,0.63])$ & $([0.36,0.45],[0.55,0.64])$ & $([0.42,0.50][0.52,0.58])$ & $([0.27,0.45],[0.65,0.73])$ \\
\hline
\end{tabular}

TABLE 5: IVIFN evaluation information by $D_{5}$.

\begin{tabular}{ccccc}
\hline & $Z_{1}$ & $Z_{2}$ & $Z_{3}$ & $Z_{4}$ \\
\hline$Y_{1}$ & $([0.63,0.66],[0.69,0.37])$ & $([0.45,0.46],[0.48,0.55])$ & $([0.39,0.45],[0.59,0.61])$ & $([0.43,0.47],[0.54,0.57])$ \\
$Y_{2}$ & $([0.43,0.47],[0.52,0.57])$ & $([0.37,0.43],[0.59,0.63])$ & $([0.40,0.50],[0.52,0.60])$ & $([0.41,0.48],[0.52,0.59])$ \\
$Y_{3}$ & $([0.47,0.49],[0.51,0.53])$ & $([0.29,0.35],[0.65,0.71])$ & $([0.42,0.48],[0.53,0.58])$ & $([0.27,0.43],[0.67,0.73])$ \\
$Y_{4}$ & $([0.41,0.49],[0.52,0.59])$ & $([0.43,0.47],[0.52,0.57])$ & $([0.46,0.48],[0.52,0.54])$ & $([0.19,0.38],[0.67,0.81])$ \\
$Y_{5}$ & $([0.33,0.45],[0.64,0.67])$ & $([0.48,0.50],[0.51,0.52])$ & $([0.44,0.46],[0.53,0.56])$ & $([0.21,0.37],[0.68,0.79])$ \\
\hline
\end{tabular}

Step 3: decide the attribute weights $z_{j}(j=1,2, \ldots, n)$ by making use of the CRITIC method as recorded in Table 8.

Step 4: depending on the calculated results of Table 8, the value of average solution (AV) can be obtained on the basis of all proposed attributes by equations (19) and (20) (see Table 9).

Step 5: relying on the results of AV, the PDA and NDA can be calculated by utilizing equations (21) and (22) (see Tables 10 and 11).
Step 6: on the basis of equation (23) and attribute weighting vector $\omega=(0.1311,0.2162,0.2233,0.4094)$, the values of $\mathrm{SP}_{i}$ and $\mathrm{SN}_{i}$ can be calculated:

$$
\begin{aligned}
\mathrm{SP}_{1} & =0.0018, \mathrm{SP}_{2}=0.2063, \mathrm{SP}_{3}=0.0375, \mathrm{SP}_{4} \\
& =0.0659, \mathrm{SP}_{5}=0.0000 \\
\mathrm{SN}_{1} & =0.1379, \mathrm{SN}_{2}=0.0356, \mathrm{SN}_{3}=0.0689, \mathrm{SN}_{4} \\
& =0.1052, \mathrm{SN}_{5}=0.0338
\end{aligned}
$$




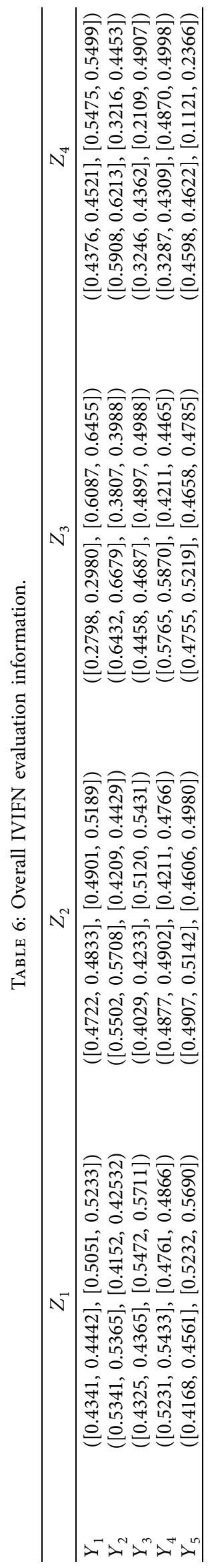







TABLE 8: The attribute weights $z_{j}$.

\begin{tabular}{ccccc}
\hline & $Z_{1}$ & $Z_{2}$ & $Z_{3}$ & $Z_{4}$ \\
\hline$Z_{j}$ & 0.1311 & 0.2162 & 0.2233 & 0.4094 \\
\hline
\end{tabular}

TABLE 9: The value of average solution.

\begin{tabular}{lc}
\hline & Average solution \\
\hline$Z_{1}$ & $([0.4286,0.4782],[0.4784,0.5231])$ \\
$Z_{2}$ & $([0.5219,0.5690],[0.4221,0.4410])$ \\
$Z_{3}$ & $([0.4522,0.4897],[0.4588,0.5099])$ \\
$Z_{4}$ & $([0.4308,0.4906],[0.3265,0.4128])$ \\
\hline
\end{tabular}

TABle 10: The results of $\mathrm{PDA}_{i j}$.

\begin{tabular}{ccccc}
\hline & $Z_{1}$ & $Z_{2}$ & $Z_{3}$ & $Z_{4}$ \\
\hline$Y_{1}$ & 0.0000 & 0.0054 & 0.0000 & 0.0000 \\
$Y_{2}$ & 0.1236 & 0.0000 & 0.2833 & 0.3164 \\
$Y_{3}$ & 0.0000 & 0.1436 & 0.0000 & 0.0000 \\
$Y_{4}$ & 0.0929 & 0.0000 & 0.1565 & 0.0000 \\
$Y_{5}$ & 0.0000 & 0.0000 & 0.0000 & 0.0000 \\
\hline
\end{tabular}

TABle 11: The results of $\mathrm{NDA}_{i j}$.

\begin{tabular}{ccccc}
\hline & $Z_{1}$ & $Z_{2}$ & $Z_{3}$ & $Z_{4}$ \\
\hline$Y_{1}$ & 0.0084 & 0.0000 & 0.3875 & 0.0288 \\
$Y_{2}$ & 0.0000 & 0.1477 & 0.0000 & 0.0000 \\
$Y_{3}$ & 0.0938 & 0.0000 & 0.1252 & 0.0245 \\
$Y_{4}$ & 0.0000 & 0.0038 & 0.0000 & 0.3567 \\
$Y_{5}$ & 0.1293 & 0.0368 & 0.0359 & 0.0046 \\
\hline
\end{tabular}

Step 7: the results of Step 6 could be normalized by equation (24):

$$
\begin{aligned}
\mathrm{NSP}_{1} & =0.0063, \mathrm{NSP}_{2}=1.0000, \mathrm{NSP}_{3}=0.1200, \mathrm{NSP}_{4} \\
& =0.3037, \mathrm{NSP}_{5}=0.0000, \\
\mathrm{NSN}_{1} & =0.0000, \mathrm{NSN}_{2}=0.7528, \mathrm{NSN}_{3}=0.5462, \mathrm{NSN}_{4} \\
& =0.1982, \mathrm{NSN}_{5}=0.7361 .
\end{aligned}
$$

Step 8: on the basis of each alternative's $\mathrm{NSP}_{i}$ and $\mathrm{NSN}_{i}$, the values of AS are calculated:

$$
\begin{aligned}
\mathrm{AS}_{1} & =0.0038, \mathrm{AS}_{2}=0.8715, \mathrm{AS}_{3}=0.3581, \mathrm{AS}_{4} \\
& =0.2613, \mathrm{AS}_{5}=0.3732 .
\end{aligned}
$$

Step 9: according to the AS, all the alternatives can be ranked; the higher the value of AS is, the optimal alternative will be selected. Evidently, the rank of these five alternatives is $Y_{2}>Y_{5}>Y_{3}>Y_{4}>Y_{1}$, and $Y_{2}$ is the best wireless sensor network.
4.2. Comparative Analysis. In this part, our developed method is compared with some other methods to illustrate its superiority.

First of all, our presented method is compared with IVIFWA and IVIFWG operators [44]. For the IVIFWA operator, the calculated result is $S\left(Y_{1}\right)=0.4364$, $S\left(Y_{2}\right)=0.5806, \quad S\left(Y_{3}\right)=0.4852, \quad S\left(Y_{4}\right)=0.4941, \quad$ and $S\left(Y_{5}\right)=0.4752$. Thus, the ranking order is $Y_{2}>Y_{4}>Y_{3}>Y_{5}>Y_{1}$. For the IVIFWG operator, the calculated result is $S\left(Y_{1}\right)=0.4197, \quad S\left(Y_{2}\right)=0.5708$, $S\left(Y_{3}\right)=0.4762, S\left(Y_{4}\right)=0.4673$, and $S\left(Y_{5}\right)=0.4733$. So, the ranking order is $Y_{2}>Y_{3}>Y_{5}>Y_{4}>Y_{1}$.

Furthermore, our presented method is compared with the modified VIKOR method with IVIFSs [55]. Then, we can obtain the calculation result. The closest ideal score values are determined as $\mathrm{CI}^{*}\left(Y_{1}\right)=1.0000, \mathrm{CI}^{*}\left(Y_{2}\right)=0.1705$, $\mathrm{CI}^{*}\left(Y_{3}\right)=0.3404, \mathrm{CI}^{*}\left(Y_{4}\right)=0.6723$, and $\mathrm{CI}^{*}\left(Y_{5}\right)=0.4065$. And the farthest worst score values are determined as $\mathrm{CI}^{-}\left(Y_{1}\right)=0.0000, \mathrm{CI}^{-}\left(Y_{2}\right)=0.5103, \mathrm{CI}^{-}\left(Y_{3}\right)=0.7247$, $\mathrm{CI}^{-}\left(Y_{4}\right)=0.1856$, and $\mathrm{CI}^{-}\left(Y_{5}\right)=0.1139$. Then, each alternative's relative closeness is calculated as $\mathrm{DRC}_{1}=1.0000$, $\mathrm{DRC}_{2}=0.2652, \quad \mathrm{DRC}_{3}=0.3265, \quad \mathrm{DRC}_{4}=0.7982, \quad$ and $\mathrm{DRC}_{5}=0.8077$. Hence, the ranking order of alternatives is $Y_{2}>Y_{3}>Y_{4}>Y_{5}>Y_{1}$.

In the end, our presented method is compared with GRA-based IVIFSs [56]. Then, we can obtain the calculation result. The grey relational grades of each alternative are calculated as $\gamma_{1}=0.8398, \quad \gamma_{2}=1.0000, \quad \gamma_{3}=0.8307$, $\gamma_{4}=0.8821$, and $\gamma_{5}=0.8672$. Therefore, the ranking order of alternatives is $Y_{2}>Y_{4}>Y_{5}>Y_{1}>Y_{3}$.

Eventually, the results of dissimilar methods are recorded in Table 12.

Derived from Table 12, it is evident that the optimal wireless sensor network is $Y_{2}$ in the mentioned methods, while the worst choice is $Y_{1}$ in most situations. In other words, these methods' ranking results are slightly different. Different methods could effectively tackle MAGDM issues from different kinds of angles. IVIFWA and IVIFWG operators emphasize to aggregate evaluation information. The modified VIKOR method with IVIFSs emphasizes the closest to the ideal solution and the farthest to the worst solution. The GRA-based IVIFSs emphasize the degree of similarity or difference between two sequences on the basis of the relation. However, our developed method emphasizes to calculate the expected function from the average solution. Compared with the aforementioned methods, it is more practical and effective since the procedures of calculation are simpler, and it is more convenient to apply to the practical situations. 
TABLE 12: Evaluation results of dissimilar methods.

\begin{tabular}{lccc}
\hline Methods & Ranking order & The optimal alternative & The worst alternative \\
\hline IVIFWA & $Y_{2}>Y_{4}>Y_{3}>Y_{5}>Y_{1}$ & $Y_{2}$ & $Y_{1}$ \\
IVIFWG & $Y_{2}>Y_{3}>Y_{5}>Y_{4}>Y_{1}$ & $Y_{2}$ & $Y_{1}$ \\
The modified VIKOR & $Y_{2}>Y_{3}>Y_{4}>Y_{5}>Y_{1}$ & $Y_{2}$ & $Y_{1}$ \\
The GRA method & $Y_{2}>Y_{4}>Y_{5}>Y_{1}>Y_{3}$ & $Y_{2}$ & $Y_{3}$ \\
The developed method & $Y_{2}>Y_{5}>Y_{3}>Y_{4}>Y_{1}$ & $Y_{2}$ & $Y_{1}$ \\
\hline
\end{tabular}

\section{Conclusion}

In this paper, IVIF-EDAS method is developed to tackle the MAGDM issues based on the description of the EDAS method and some fundamental notions of IVIFSs. To begin with, the fundamental information of IVIFSs is simply introduced. After that, the IVIFWA and IVIFWG operators are utilized to integrate the IVIFNs. Subsequently, relying on the CRITIC method, the attributes' weights are decided. In addition, applying the EDAS method to the IVIFSs, a new method is designed, and the calculating procedures are listed in detail. Finally, an application for assessing the service quality of wireless sensor networks has been given to show the superiority of this novel method, and comparative analysis between the IVIF-EDAS method and some other methods could also be made to further verify some merits of such a method. In our future works, the EDAS method and the CRITIC method will be extensively applied in different uncertain and ambiguous environments [57-67].

\section{Data Availability}

The data used to support the findings of this study are included within the article.

\section{Conflicts of Interest}

The authors declare no conflicts of interest.

\section{References}

[1] L. A. Zadeh, "Fuzzy sets," Information and Control, vol. 8, no. 3, pp. 338-353, 1965.

[2] K. T. Atanassov, "Intuitionistic fuzzy sets," Fuzzy Sets and Systems, vol. 20, no. 1, pp. 87-96, 1986.

[3] X. J. Gou, Z. S. Xu, and Q. Lei, "New operational laws and aggregation method of intuitionistic fuzzy information," Journal of Intelligent \& Fuzzy Systems, vol. 30, pp. 129-141, 2016.

[4] Y. He, Z. He, and H. Huang, "Decision making with the generalized intuitionistic fuzzy power interaction averaging operators," Soft Computing, vol. 21, no. 5, pp. 1129-1144, 2017.

[5] L. Zhang and Y. He, "Extensions of intuitionistic fuzzy geometric interaction operators and their application to cognitive microcredit origination," Cognitive Computation, vol. 11, no. 5, pp. 748-760, 2019.

[6] M. Li and C. Wu, "A distance model of intuitionistic fuzzy cross entropy to solve preference problem on alternatives," Mathematical Problems in Engineering, vol. 2016, Article ID 8324124, 9 pages, 2016.

[7] R. X. Liang, S. S. He, J. Q. Wang, K. Chen, and L. Li, “An extended mabac method for multi-criteria group decision- making problems based on correlative inputs of intuitionistic fuzzy information," Computational \& Applied Mathematics, vol. 38, p. 28, 2019.

[8] M. S. Khan and Q. M. D. Lohani, "IEEE, a similarity measure for atanassov intuitionistic fuzzy sets and its application to clustering," in In Proceedings of the 2016 International Workshop on Computational Intelligence (IWCI), Dhaka, Bangladesh, Decemebr 2016.

[9] S.-M. Chen, S.-H. Cheng, and T.-C. Lan, "Multicriteria decision making based on the topsis method and similarity measures between intuitionistic fuzzy values," Information Sciences, vol. 367-368, pp. 279-295, 2016.

[10] P. Li, J. Liu, S. F. Liu, X. Su, and J. Wu, "Grey target method for intuitionistic fuzzy decision making based on grey incidence analysis," Journal of Grey System, vol. 28, pp. 96-109, 2016.

[11] F. Lei, G. W. Wei, J. P. Lu, C. Wei, and J. Wu, "Gra method for probabilistic linguistic multiple attribute group decision making with incomplete weight information and its application to waste incineration plants location problem," International Journal of Computational Intelligence Systems, vol. 12, pp. 1547-1556, 2019.

[12] H. Garg, "Novel intuitionistic fuzzy decision making method based on an improved operation laws and its application," Engineering Applications of Artificial Intelligence, vol. 60, pp. 164-174, 2017.

[13] P. Gupta, H. D. Arora, and P. Tiwari, "Generalized entropy for intuitionistic fuzzy sets," Malaysian Journal of Mathematical Sciences, vol. 10, pp. 209-220, 2016.

[14] J. Lu, C. Wei, J. Wu, and G. Wei, "Topsis method for probabilistic linguistic magdm with entropy weight and its application to supplier selection of new agricultural machinery products," Entropy, vol. 21, no. 10, p. 953, 2019.

[15] T. Bao, X. Xie, P. Long, and Z. Wei, "Madm method based on prospect theory and evidential reasoning approach with unknown attribute weights under intuitionistic fuzzy environment," Expert Systems with Applications, vol. 88, pp. 305-317, 2017.

[16] J. W. Gan and L. Luo, "Using dematel and intuitionistic fuzzy sets to identify critical factors influencing the recycling rate of end-of-life vehicles in China," Sustainability, vol. 9, no. 10, 2017.

[17] P. Gupta, M. K. Mehlawat, N. Grover, and W. Chen, "Modified intuitionistic fuzzy sir approach with an application to supplier selection," Journal of Intelligent \& Fuzzy Systems, vol. 32, no. 6, pp. 4431-4441, 2017.

[18] R. Krishankumar, K. S. Ravichandran, and A. B. Saeid, “A new extension to promethee under intuitionistic fuzzy environment for solving supplier selection problem with linguistic preferences," Applied Soft Computing, vol. 60, pp. 564-576, 2017.

[19] X. Luo and X. Z. Wang, "Extended vikor method for intuitionistic fuzzy multiattribute decision-making based on a new distance measure," Mathematical Problems in Engineering, vol. 2017, Article ID 4072486, 16 pages, 2017. 
[20] Z. Hao, Z. Xu, H. Zhao, and R. Zhang, "Novel intuitionistic fuzzy decision making models in the framework of decision field theory," Information Fusion, vol. 33, pp. 57-70, 2017.

[21] L. Zhang, J. Zhan, and Y. Yao, "Intuitionistic fuzzy topsis method based on cvpifrs models: an application to biomedical problems," Information Sciences, vol. 517, pp. 315-339, 2020.

[22] H. Garg, "Generalized intuitionistic fuzzy entropy-based approach for solving multi-attribute decision-making problems with unknown attribute weights," Proceedings of the National Academy of Sciences, India Section A: Physical Sciences, vol. 89, no. 1, pp. 129-139, 2019.

[23] P. Liu, J. Liu, and S.-M. Chen, "Some intuitionistic fuzzy dombi bonferroni mean operators and their application to multi-attribute group decision making," Journal of the Operational Research Society, vol. 69, no. 1, pp. 1-24, 2018.

[24] G. Wei, J. Wu, C. Wei, J. Wang, and J. Lu, "Models for madm with 2-tuple linguistic neutrosophic dombi bonferroni mean operators," IEEE Access, vol. 7, pp. 108878-108905, 2019.

[25] F. Jin, Z. Ni, H. Chen, and Y. Li, "Approaches to group decision making with intuitionistic fuzzy preference relations based on multiplicative consistency," Knowledge-Based Systems, vol. 97, pp. 48-59, 2016.

[26] L. Wu, H. Gao, and C. Wei, "Vikor method for financing risk assessment of rural tourism projects under interval-valued intuitionistic fuzzy environment," Journal of Intelligent \& Fuzzy Systems, vol. 37, no. 2, pp. 2001-2008, 2019.

[27] L. Wu, J. Wang, and H. Gao, "Models for competiveness evaluation of tourist destination with some interval-valued intuitionistic fuzzy hamy mean operators," Journal of Intelligent \& Fuzzy Systems, vol. 36, no. 6, pp. 5693-5709, 2019.

[28] L. Wu, G. Wei, J. Wu, and C. Wei, "Some interval-valued intuitionistic fuzzy dombi heronian mean operators and their application for evaluating the ecological value of forest ecological tourism demonstration areas," International Journal of Environmental Research and Public Health, vol. 17, no. 3, p. 829, 2020.

[29] S.-M. Chen and L.-W. Kuo, "Multiattribute decision making based on non-linear programming methodology with hyperbolic function and interval-valued intuitionistic fuzzy values," Information Sciences, vol. 453, pp. 379-388, 2018.

[30] J. Lu and C. Wei, "Todim method for performance appraisal on social-integration-based rural reconstruction with interval-valued intuitionistic fuzzy information," Journal of Intelligent \& Fuzzy Systems, vol. 37, no. 2, pp. 1731-1740, 2019.

[31] H. Garg and K. Kumar, "Group decision making approach based on possibility degree measures and the linguistic intuitionistic fuzzy aggregation operators using einstein norm operations," Journal of Multiple-Valued Logic and Soft Computing, vol. 31, pp. 175-209, 2018.

[32] H. Garg and R. Arora, "Generalized intuitionistic fuzzy soft power aggregation operator based on $t$ norm and their application in multicriteria decision-making," International Journal of Intelligent Systems, vol. 34, no. 2, pp. 215-246, 2019.

[33] M. Keshavarz Ghorabaee, E. K. Zavadskas, L. Olfat, and Z. Turskis, "Multi-criteria inventory classification using a new method of evaluation based on distance from average solution (edas)," Informatica, vol. 26, no. 3, pp. 435-451, 2015.

[34] M. K. Ghorabaee, E. K. Zavadskas, M. Amiri, and Z. Turskis, "Extended edas method for fuzzy multi-criteria decisionmaking: an application to supplier selection," International Journal of Computers Communications \& Control, vol. 11, no. 3, pp. 358-371, 2016.

[35] M. Keshavarz Ghorabaee, M. Amiri, E. K. Zavadskas, Z. Turskis, and J. Antucheviciene, "Stochastic edas method for multi-criteria decision-making with normally distributed data," Journal of Intelligent \& Fuzzy Systems, vol. 33, no. 3, pp. 1627-1638, 2017.

[36] X. Peng and C. Liu, "Algorithms for neutrosophic soft decision making based on edas, new similarity measure and level soft set," Journal of Intelligent \& Fuzzy Systems, vol. 32, no. 1, pp. 955-968, 2017.

[37] C. Kahraman, M. Keshavarz Ghorabaee, E. K. Zavadskas, S. Cevik Onar, M. Yazdani, and B. Oztaysi, "Intuitionistic fuzzy edas method: an application to solid waste disposal site selection," Journal of Environmental Engineering and Landscape Management, vol. 25, no. 1, pp. 1-12, 2017.

[38] Y. He, F. Lei, G. W. Wei, R. Wang, J. Wu, and C. Wei, "Edas method for multiple attribute group decision making with probabilistic uncertain linguistic information and its application to green supplier selection," International Journal of Computational Intelligence Systems, vol. 12, no. 2, pp. 1361-1370, 2019.

[39] M. Keshavarz-Ghorabaee, M. Amiri, E. K. Zavadskas, Z. Turskis, and J. Antucheviciene, "A comparative analysis of the rank reversal phenomenon in the edas and topsis methods," Economic Computation and Economic Cybernetics Studies and Research, vol. 52, pp. 121-134, 2018.

[40] P. Wang, J. Wang, and G. Wei, "Edas method for multiple criteria group decision making under 2-tuple linguistic neutrosophic environment," Journal of Intelligent \& Fuzzy Systems, vol. 37, no. 2, pp. 1597-1608, 2019.

[41] Z. X. Li, G. W. Wei, R. Wang, J. Wu, C. Wei, and Y. Wei, "Edas method for multiple attribute group decision making under $q$ rung orthopair fuzzy environment," Technological and Economic Development of Economy, vol. 26, no. 1, pp. 86-102, 2020.

[42] X. Feng, C. Wei, and Q. Liu, "Edas method for extended hesitant fuzzy linguistic multi-criteria decision making," International Journal of Fuzzy Systems, vol. 20, no. 8, pp. 2470-2483, 2018.

[43] A. Karasan and C. Kahraman, "A novel interval-valued neutrosophic edas method: prioritization of the united nations national sustainable development goals," Soft Computing, vol. 22, no. 15, pp. 4891-4906, 2018.

[44] Z. Xu and R. R. Yager, "Some geometric aggregation operators based on intuitionistic fuzzy sets," International Journal of General Systems, vol. 35, no. 4, pp. 417-433, 2006.

[45] H.-W. Liu and G.-J. Wang, "Multi-criteria decision-making methods based on intuitionistic fuzzy sets," European Journal of Operational Research, vol. 179, no. 1, pp. 220-233, 2007.

[46] D. Diakoulaki, G. Mavrotas, and L. Papayannakis, "Determining objective weights in multiple criteria problems: the critic method," Computers \& Operations Research, vol. 22, no. 7, pp. 763-770, 1995.

[47] X. Deng, J. Wang, and G. Wei, "Some 2-tuple linguistic pythagorean heronian mean operators and their application to multiple attribute decision-making," Journal of Experimental \& Theoretical Artificial Intelligence, vol. 31, no. 4, pp. 555-574, 2019.

[48] X. Y. Tang and G. W. Wei, "Dual hesitant pythagorean fuzzy bonferroni mean operators in multi-attribute decision making," Archives of Control Sciences, vol. 29, pp. 339-386, 2019.

[49] G. Wei, S. Zhang, J. Lu, J. Wu, and C. Wei, "An extended bidirectional projection method for picture fuzzy magdm and its application to safety assessment of construction project," IEEE Access, vol. 7, pp. 166138-166147, 2019.

[50] X. Deng and H. Gao, "Todim method for multiple attribute decision making with 2-tuple linguistic pythagorean fuzzy information," Journal of Intelligent \& Fuzzy Systems, vol. 37, no. 2, pp. 1769-1780, 2019. 
[51] H. Gao, M. Lu, and Y. Wei, "Dual hesitant bipolar fuzzy hamacher aggregation operators and their applications to multiple attribute decision making," Journal of Intelligent \& Fuzzy Systems, vol. 37, no. 4, pp. 5755-5766, 2019.

[52] Z. Li and M. Lu, "Some novel similarity and distance measures of pythagorean fuzzy sets and their applications," Journal of Intelligent \& Fuzzy Systems, vol. 37, no. 2, pp. 1781-1799, 2019.

[53] J. Wang, H. Gao, and M. Lu, "Approaches to strategic supplier selection under interval neutrosophic environment," Journal of Intelligent \& Fuzzy Systems, vol. 37, no. 2, pp. 1707-1730, 2019.

[54] R. Wang, "Research on the application of the financial investment risk appraisal models with some interval number muirhead mean operators," Journal of Intelligent \& Fuzzy Systems, vol. 37, no. 2, pp. 1741-1752, 2019.

[55] S. Zeng, S.-M. Chen, and L.-W. Kuo, "Multiattribute decision making based on novel score function of intuitionistic fuzzy values and modified vikor method," Information Sciences, vol. 488, pp. 76-92, 2019.

[56] S.-F. Zhang and S.-Y. Liu, "A gra-based intuitionistic fuzzy multi-criteria group decision making method for personnel selection," Expert Systems with Applications, vol. 38, no. 9, pp. 11401-11405, 2011.

[57] E. K. Zavadskas, J. Antucheviciene, and P. Chatterjee, "Multiple-criteria decision-making ( $\mathrm{mcdm})$ techniques for business processes information management," Information, vol. 10, no. 1, 2019.

[58] E. K. Zavadskas, J. Antucheviciene, and S. Kar, "Multi-objective and multi-attribute optimization for sustainable development decision aiding," Sustainability, vol. 11, 2019.

[59] G. Wei, Y. Tang, M. Zhao, R. Lin, and J. Wu, "Selecting the low-carbon tourism destination: based on pythagorean fuzzy taxonomy method," Mathematics, vol. 8, no. 5, p. 832, 2020.

[60] P. Liu and H. Li, "Interval-valued intuitionistic fuzzy power bonferroni aggregation operators and their application to group decision making," Cognitive Computation, vol. 9, no. 4, pp. 494-512, 2017.

[61] S. Zeng, C. Llopis-Albert, and Y. Zhang, "A novel induced aggregation method for intuitionistic fuzzy set and its application in multiple attribute group decision making," International Journal of Intelligent Systems, vol. 33, no. 11, pp. 2175-2188, 2018.

[62] X. Gou and Z. Xu, "Novel basic operational laws for linguistic terms, hesitant fuzzy linguistic term sets and probabilistic linguistic term sets," Information Sciences, vol. 372, pp. 407-427, 2016.

[63] G. Wei, J. Lu, C. Wei, and J. Wu, "Probabilistic linguistic gra method for multiple attribute group decision making," Journal of Intelligent \& Fuzzy Systems, vol. 38, no. 4, pp. 4721-4732, 2020.

[64] H. Jiang, J. Zhan, B. Sun, and J. C. R. Alcantud, "An madm approach to covering-based variable precision fuzzy rough sets: an application to medical diagnosis," International Journal of Machine Learning and Cybernetics, 2020.

[65] X. Ma, J. Zhan, B. Sun, and J. C. R. Alcantud, "Novel classes of coverings based multigranulation fuzzy rough sets and corresponding applications to multiple attribute group decisionmaking," Artificial Intelligence Review, 2020.

[66] J. Zhan, B. Sun, and X. Zhang, "Pf-topsis method based on cpfrs models: an application to unconventional emergency events," Computers \& Industrial Engineering, vol. 139, Article ID 106192, 2020.

[67] L. Wang and N. Li, "Pythagorean fuzzy interaction power bonferroni mean aggregation operators in multiple attribute decision making," International Journal of Intelligent Systems, vol. 35, no. 1, pp. 150-183, 2020. 